\title{
Quality of life in children with familial Mediterranean fever
}

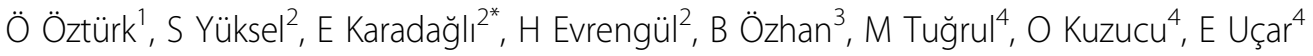 \\ From 8th International Congress of Familial Mediterranean Fever and Systemic Autoinflammatory Diseases \\ Dresden, Germany. 30 September - 3 October 2015
}

\section{Objective}

Familial Mediterranean fever (FMF) is a lifelong disorder, characterized by self-limited and recurrent attacks of fever and polyserositis. It is known that many chronic diseases have a negative effect on quality of life (QoL) multidimensionally. In our study, we aimed to assess the quality of life and psychological factors (anxiety and depression) in children with FMF.

\section{Method}

A prospective cross-sectional study was conducted between September 2013 and September 2014. A total of 70 consecutive children with FMF who were diagnosed according to the Tel-Hashomer and Yalçınkaya criteria during the attack free period and 70 healthy children who were matched in terms of age and sex were enrolled. The Pediatric Quality of Life Inventory 4.0 (PedsQLTM 4.0), Child Depression Inventory (CDI) and Screen for Child Anxiety and Related Disorders (SCARED) were used for the psychosocial assessment.

\section{Results}

Mean age of the patients (27 girls and 43 boys) was 11 \pm 3 years. The physical health, psychosocial health and total summary scores of the children with FMF were significantly lower than healthy children. In terms of sub dimension of psychosocial health, in the children with FMF, emotional functioning and school functioning domains' scores were significantly lower than healthy children. Depression and anxiety scores were higher in the children with FMF than in healthy children.

\section{Conclusion}

We found that the children with FMF have high level of depression and poorer QoL. FMF is a life-long disorder that has not only physical but also psychosocial

Table 1

\begin{tabular}{|c|c|c|c|c|}
\hline & & Children with FMF & Healthy Children & $p$ \\
\hline & & Mean \pm SD & Mean \pm SD & \\
\hline Physical Health & & $77,7 \pm 13,19$ & $88,93 \pm 10,17$ & $<0.001^{*}$ \\
\hline \multirow[t]{4}{*}{ Psychosocial Health } & & $77,43 \pm 13,04$ & $87,26 \pm 5,18$ & $<0.001^{*}$ \\
\hline & Social Functioning & $90,14 \pm 12,94$ & $89,93 \pm 7,54$ & 0.093 \\
\hline & Emotional Functioning & $73,29 \pm 19,85$ & $88,43 \pm 6,23$ & $<0.001^{*}$ \\
\hline & School Functioning & $68,86 \pm 16,07$ & $83,43 \pm 13,47$ & $<0.001^{*}$ \\
\hline Total Summary Score & & $77,5 \pm 11,26$ & $87,68 \pm 4,68$ & $<0.001^{*}$ \\
\hline Depression Scores & & $15,43 \pm 5,75$ & $9,87 \pm 2,83$ & $<0.001^{*}$ \\
\hline Anxiety Scores & & $22,9 \pm 12,63$ & $17,21 \pm 7$ & $0.004^{*}$ \\
\hline
\end{tabular}

Independent samples $\mathrm{t}$ test, *statistical significance

\footnotetext{
${ }^{2}$ Pamukkale University, School of Medicine, Pediatric Rheumatology, Denizli,

Turkey

Full list of author information is available at the end of the article
} 
impairments for the affected children. Therefore a biopsychosocial approach should be essential to treatment of the FMF.

\section{Authors' details}

'Pamukkale University, School of Medicine, Child and Adolescent Psychiatry, Denizli, Turkey. ${ }^{2}$ Pamukkale University, School of Medicine, Pediatric

Rheumatology, Denizli, Turkey. ${ }^{3}$ Pamukkale University, School of Medicine,

Pediatrics, Denizli, Turkey. ${ }^{4}$ Pamukkale University, School of Medicine, Medical

Student, Denizli, Turkey.

Published: 28 September 2015

- Convenient online submission

- Thorough peer review

- No space constraints or color figure charges

- Immediate publication on acceptance

- Inclusion in PubMed, CAS, Scopus and Google Scholar

- Research which is freely available for redistribution 